\title{
TIME-SITE SURVEY OF SUBSTANCE USE, SEXUAL BEHAVIOURS AND HIV-TESTING PRACTICES AMONG WOMEN ATTENDING SOCIAL VENUES IN PRAGUE
}

\author{
M. Susan Stemmler ${ }^{1,3}$, Timothy M. Hall1, Petr Prokopík², Steven Shoptaw ${ }^{1}$ \\ ${ }^{1}$ Center for Behavioral and Addiction Medicine, David Geffen School of Medicine, University of California, Los Angeles, CA, United States \\ ${ }^{2}$ Charles University, Prague, Czech Republic \\ ${ }^{3}$ California State University, Dominguez Hills, Carson, CA, United States
}

\section{SUMMARY}

Aim: The rates of HIV acquired through heterosexual contact are increasing in the Czech Republic. This study explored potential HIV risk associations with alcohol, illicit drugs and sexual behaviours among adults from a community-based sample attending gay-and non-gay venues in Prague.

Methods: Women attending bars, cafes and beer gardens in central Prague responded to the self-administered, time-site survey. Alcohol use was measured by the AUDIT-C and CAGE questionnaires. Sexual network structuring identified number, gender and coital frequency with current and recent sexual partners. Statistical analysis included central tendency, chi-square and logistic regression. Female participants $(n=124)$ ranged from 18 to 67 years of age (mean 29 years); $25 \%$ self-identified as non-heterosexual.

Results: We found alcohol to be the preferred drug of choice. Younger heterosexual women with new and casual sexual partners were more likely to use alcohol excessively. Women with children reported the least alcohol use. Sixty percent of the sample had never used condoms; condom-use was associated with longer relationship duration and discussions about HIV status with a sexual partner; non-use tended to occur among unmarried women with multiple male partners in short, serial sexual relationships. Women who sought HIV testing tended to be younger and more self-identified as non-heterosexual. Protective practices were rarely reported even when HIV transmission increases via heterosexual sexual partnering.

Conclusion: Further research is recommended regarding cultural and contextual influences on HIV risk behaviours among Czech women.

Key words: Czech Republic, women, alcohol consumption, sexual behaviour, HIV risk, female homosexuality

Address for correspondence: S. Stemmler, Center for Behavioral and Addiction Medicine, David Geffen School of Medicine, University of California, Los Angeles, CA, United States. E-mail: msstemmler@csudh.edu

\section{INTRODUCTION}

Since the Czech Republic regained independence, Czech society has undergone substantial change in its experience of alcohol, drug abuse and HIV infection. Prior political restrictions on travel and trade effectively curtailed HIV risk behaviours; consequently, then Czechoslovakia escaped the initial waves of the European HIV/AIDS epidemic. Today, the incidence of HIV infection has increased fourfold from a low baseline. Diagnosis of non-injection, heterosexually transmitted HIV is rising among both women and men (1).

Historically Czech society has been recognized for its high alcohol intake, often coming first among nations for per capita consumption of beer $(2,3)$; but, it has had rather low exposure to other drugs of abuse, except marijuana and methamphetamine, locally known as pervitin (4). A recent study found that $21.8 \%$ of young Czech adults reported use of marijuana within the previous year (5) and methamphetamine use has raised concern that it could become a risk factor for HIV infection as in North America $(6,7)$.

A recent review of Czech substance abuse treatment data documents two dramatic re-characterizations of drug abuse over the last two decades. First, young adult women have drifted towards problematic alcohol consumption that was typically observed among Czech men $(8,9)$. The gender ratio for substance abuse treatment admissions, once noted as $4: 1$, men to women, has gradually shifted to $2: 1$, reflecting increased prevalence and possibly greater severity of substance use disorders among Czech women $(10,11)$. Second, although alcohol was the primary substance named in $75 \%$ of all treatment admissions, recent data indicate that treatment admissions for alcohol have decreased and treatment for pervitin (12) and opiates have increased. Also, among Czech women, treatment admissions for the abuse of sedatives and hypnotics signal a shift in drug use (10).

Prior to 1989, Czechoslovakia had low prevalence of HIV and sexually transmitted infections compared to Western European countries. The introduction of hormonal birth control methods made reliable contraception options available to Czech women. Birth control pills reformed reproductive behaviours, triggering delayed age for first childbearing which eventually came to match the reproductive patterns of Czech women with women in other European countries $(13,14)$. Hormonal contraception is now the popular choice over barrier protection (13, 15-17). However, little is known about condom use as barrier protection against HIV or sexually transmitted infections. 
The countrywide prevalence for HIV infections remains low at $<0.014 \%$ in the Czech general population (1), fewer than 2,000 people are living with HIV in a country of 10.4 million (as of the 2011 census). Public health concerns are mounting with new HIV infections and the increasing number of individuals living with HIV/AIDS. HIV transmission among men who have sex with men (MSM) accounted for $73 \%$ of the new HIV infections and heterosexual, non-injection transmission accounted for $13.7 \%$ (212) of newly diagnosed cases in 2012. Heterosexual transmitted cases make up $29.7 \%$ of cumulative cases (1).

Czech women are being diagnosed with HIV during mandatory prenatal testing, often in the absence of traditional high-risk behavioural factors. Four new cases of HIV were diagnosed from 134,716 prenatally tested women in 2010 and three were identified from 122,709 in 2011 (1). Fortunately, proactive anti-viral treatment of pregnant women has kept HIV transmission from mother to child rare (18). The Czech National Reference Laboratory data has indicated a $12.7 \%$ increase of HIV prevalence among women during 2012 (19).

During the first HIV epidemic in Europe, the Czech Ministry of Health devoted significant resources for public education campaigns to forestall HIV transmission. HIV antibody testing and needle exchange programmes were made available in public primary care clinics and at a non-governmental agency in Prague (House of Light) (20). As the HIV epidemic failed to manifest and public and media attention waned (21), annual funding of HIV prevention efforts was scaled back. Since 2011, funding for HIV/AIDS treatment has increased (20).

Prague is the capital and largest city with 1.26 million people in the municipality and 2.3 million in the metropolitan area (data acquired from the Czech Statistical Office). It has international contact through tourism, business and education. Little information exists from community-based, non-clinical samples about behaviours associated with alcohol and drug use, and sexual HIV risk behaviours by heterosexual or non-heterosexual women. We also lack knowledge of voluntary HIV testing of Czech women. This paper explores survey responses of adult Czech women about their use of alcohol, drugs and sexual conduct that can influence HIV risk. The intent of this research is to identify both harmful and protective behaviours relating to HIV risk.

\section{MATERIALS AND METHODS}

\section{Design}

The study protocol was approved by the Office of Human Research Protection at the University of California, Los Angeles at a time when the Czech Republic did not have protocols for reviewing social science research. Czech colleagues were consulted regarding emerging Czech standards.

\section{Inclusion Criteria}

Adults over 18 years of age were invited to participate. Criteria required Czech or Slovak language fluency to read the survey questionnaire in Czech; Czech residency; and willingness and ability to provide informed consent. An English-language version of the survey was available. It was offered to a few non-Czech speakers who accompanied eligible Czech or Slovak acquaintances.

\section{Exclusion Criteria}

Individuals were not eligible to participate if they did not meet the stated criteria or if, in the opinion of the investigators, they were heavily intoxicated or unable to provide meaningful informed consent.

Permission was granted by private venue managers for the research team to recruit from their clientele during business hours. Survey administrators explained the purpose of the research, assured anonymity and privacy for participants to complete the self-administered questionnaire. Participants were given $50 \mathrm{Czech}$ crowns (Czech equivalent of $\$ 6.00$ in 2011) for completing the questionnaire. Consultant Czech colleagues assured this amount was reasonable and non-coercive. (A few participants opted to donate the compensation to a local non-governmental organization for HIV prevention.)

\section{Recruitment}

Based on prior ethnographic work in Prague, a time-site (also called time-space) stratified sampling strategy (22) was used to recruit adults attending cafés, pubs and beer gardens in central Prague (districts 1, 2 and 3) during a 4-week period during July and August 2011. Recruitment was conducted in 30-minute blocks of time on varied weekdays and weekends at 10 locations, 4 gay- or gay- and lesbian-oriented, and 6 non-gay-oriented venues. Everyone present or entering during the 30 -minute block of time was approached to participate in the survey, which took 10-15 minutes to complete. Researchers maintained a head count to determine the recruitment response rate. An oversampling of gay-oriented venues was intended to collect data on men who have sex with men (23). This manuscript reports the responses of female participants.

\section{Questionnaire}

The survey queried socio-demographic characteristics, but did not ask for employment status or socioeconomic status (SES); educational level was used as a proxy for SES. We asked participants to self-identify as heterosexual, homosexual, bisexual, or transsexual (female-to-male or male-to-female transition). We created a dichotomized variable for sexual identification because of the small number sexual minority respondents. Risk behaviours were asked in various ways, including the number and gender of casual and primary sexual partners during the last 6 months, use of condom or barrier devices during sexual encounters, and dialogues regarding HIV status with partners. Questions were adapted from the SATHCAP multi-site surveys of HIV risk behaviours (24). We assessed relationship status and the duration of the relationship. "Primary partner" was defined as someone with whom the respondent "lives/lived or often had (vaginal or anal) sexual intercourse, and towards whom (she) felt an emotional bond". We assessed marital status of the respondents (single, married, divorced, widowed, or registered partnership - a form of civil union largely equivalent to heterosexual marriage since 2006 (Czech legal code 115/2006 Coll.). Last, we asked about 
HIV testing experience, perceptions of risk, and willingness to use prophylaxis against HIV infection.

Questions from the 3-item AUDIT (25) assessed the quantity and frequency patterns of alcohol use. The CAGE screen (26) assessed alcohol abuse behaviours; a reference threshold of two or more positive responses established problematic consumption $(27,28)$. Both measures have previously been used in Czechspeaking populations $(29,30)$.

\section{Time Frame of Questions}

Most behaviours were assessed within 6 months prior to the survey. We also assessed drug use within the last 30 days and use of alcohol, drugs and/or condoms at the most recent sexual encounter within the last 6 months.

\section{Statistical Analysis}

Social and demographic characteristics were summarized by percent, mean and standard deviation. Intentional skips were planned for questions based on gender of partners and primary versus casual partners; therefore, the sample size varies for different questions. Depending on the number and distribution of the variables, test statistics were analyzed using univariate and multivariate tests. Chi-square was followed by the post hoc SidakBonferroni for pairwise correlations and to reduce the possibilities of Type I error as a result of multiple comparisons (31). Logistic regression was conducted with dichotomous variables for alcohol excess, condom use, and HIV-testing.

\section{RESULTS}

\section{Sample Characteristics}

During recruitment, 163 women were approached to participate. The refusal rate for women was approximately $30 \%$. Women were more likely to attend the social establishments in groups; when groups of women were approached, if one refused all refused. To accommodate participants who did not read or write in Czech, we offered an English version of the questionnaire. The sample comprised 124 women, 106 completed the questionnaire in Czech and 18 in English, 85\% of the respondents were Czech, $8 \%$ Slovak, 2\% Roma, and 5\% other. There was a bimodal age distribution; the largest group (66\%) of young adult women was from 18-30 years of age and the second mode were women over 50 who had been young adults prior to the end of state socialism. Generally speaking, the women were well educated, two-thirds (64\%) of the women reported university education, $35 \%$ had completed secondary school and only $6.4 \%$ had elementary education.

The majority of the women ( 95 of $124,76 \%$ ) were self-identified heterosexuals. The mean age for this group was 29 years. Non-heterosexual identification was reported by 29 (23\%) of the women; self-identification as homosexual was noted by $9 \%$, mean age 32 years; bisexual $8 \%$, mean age 24 years; and transsexual $3 \%$, mean age 23 years. Regarding marital status, 30\% reported being single, $11 \%$ married, and 5\% were divorced. Forty-seven percent responded they were in a dating relationship, and $10 \%$ claimed no relationship. Out of 99 respondents, $66 \%$ reported having a primary, sexual relationship currently or within the last 6 months. Only $15 \%$ (18) of the sample reported that they have children; most of the women with children were older than 25 years.

\section{Substance Use}

The majority (97\%) of the respondents reported using alcohol or other drugs (AOD) within the past 30 days. Of these women, $66 \%$ reported only alcohol use. The remaining women reported alcohol use with other drugs: $18.6 \%$ alcohol and marijuana, $3 \%$ alcohol and cocaine, and 1.6\% alcohol and stimulants including pervitin. Only $1.5 \%$ of the sample reported marijuana or cocaine use independent of alcohol use.

Alcohol consumption was described as $0.5 \mathrm{~L}$ of beer, $0.2 \mathrm{~L}$ of wine, or one shot or mixed drink per occasion. Generally, the respondents reported consuming 5 to 6 drinks on each occasion, $70 \%$ used alcohol on two or more occasions per week and $8 \%$ reported daily alcohol use. Excessive alcohol use was defined as five or more alcoholic drinks within a two-hour period (29). Sixty percent of the sample indicated drinking alcohol to excess within the past year. By age categories, $84 \%$ of women less than 25 years of age and $42 \%$ of women older than 25 years reported excessive alcohol use. Comparing excessive alcohol use by sexual self-identification, 55 of $94(55 \%)$ heterosexual respondents and 17 of $28(61 \%)$ of women who identified themselves as a sexual minority reported excessive alcohol use within the last year. Binge drinking was defined as periodic excessive alcohol use; it reportedly occurred weekly for $28 \%$ and monthly for $59 \%$ of the total sample.

On the CAGE questionnaire, 2 or more out of 4 positive responses indicated problematic alcohol use by $42 \%$ of the respondents. Responses included: $42 \%$ reported the need to cut down their alcohol use; 39\% reported guilt about drinking, 20\% claimed they had been criticized about their drinking, and 16\% reported drinking in the morning to steady their nerves.

We found a statistically significant relationship between excessive use of alcohol and women younger than 25 years $(\mathrm{p}<0.001$, Sidak $\mathrm{p}<0.001)$. Excessive alcohol use was positively associated with having casual male sex partners $(p<0.047$, Sidak $p<0.030)$, and with the number of new partners in the past 6 months $(\mathrm{p}<0.018$, Sidak $\mathrm{p}<0.049)$. Women who identified themselves as a sexual minority (14\%), i.e. lesbian, bisexual or transsexual, reported more frequent alcohol use, however, excessive alcohol use was comparable to the reports from heterosexual women. Having children was negatively associated with excessive drinking $(\mathrm{p}<0.015$, Sidak $\mathrm{p}<0.001)$.

\section{Sexual Risk Behaviours}

Nine of 118 (7.3\%) reported never having sexual encounters. Regardless of sexual identification, $92 \%$ of the female respondents reported having sexual encounters with men (WSM). Same-sex encounters, women having sex with women (WSW), were reported by $18 \%$ of the sample. Eighty-eight percent reported having at least one primary male sexual partner within the past year, and $73 \%$ of the WSM reported an average of three primary sexual partners (range 1 to 4 partners) within the past 6 months. Half of the women with male primary partners reported the duration of their relationship from 1 to 6 months. Sixty percent of the women 
with a same-sex primary partner reported longer than one-year duration of their relationship. Of 88 women responding to questions about casual relationships within the previous six months, $28 \%$ of women who claimed to have a primary male partner also reported between 1 to 10 casual sexual encounters. In contrast, women who reported a same-sex primary relationship reported no casual sexual partners within the same period of time.

Responses regarding safer sex practices, in particular use of condoms or barrier devices during sexual encounters, yielded very low utilization. Sixty percent of the sample reported never using condoms or barriers. Only $18 \%$ of the total sample of women reported consistent condom use. Of the women who reported having casual intimate male partners, $37 \%$ reported consistent condom use and $23 \%$ claimed never to have used condoms. Condom use was negatively associated with having casual male partners in the past 6 months $(\mathrm{p}<0.002)$ and positively associated with longer duration of the primary relationship $(p<0.003$, Sidak $p<0.012)$.

Regarding sexual encounters and alcohol or drugs use, 46 of 95 WSM respondents (48\%) reported using alcohol or other drugs (AOD) during or within two hours prior to their most recent casual sexual encounter. A significant association was noted for excessive AOD use at the time of last intercourse among women $<25$ years of age ( $p<0.006$, Sidak $p<0.005)$, findings were also significant for women older than 40 years $(\mathrm{p}<0.001$, Sidak $\mathrm{p}<0.001)$. Of 18 WSW respondents, 8 (44\%) reported AOD use with their last sexual encounter.

\section{HIV Testing and Partner Status}

Sixty-eight percent of the respondents indicated they had never tested for HIV, 15\% tested within the last 12 months and $17 \%$ had tested prior to the past year. HIV testing differed only slightly by sexual identification, $14 \%$ of heterosexual women and $21 \%$ of the non-heterosexual women had tested for HIV within the previous 12 months. Similarly, $16 \%$ of heterosexual women compared to $21 \%$ of non-heterosexual women tested for HIV prior to the last 12 months.

Forty-seven percent of the WSM with a primary intimate partner reported they knew or suspected their partner's HIV status, though only $10 \%$ claimed to have had a conversation to learn the HIV status of a casual partner. Of the $15 \mathrm{WSW}$ who responded, only two women (13\%) had discussed HIV status with a partner. Discussing HIV status was positively associated with using a condom at last sexual encounter $(p<0.001$, Sidak $p<0.001)$. Finally, pre- or post-exposure HIV prophylaxis was known to only $10 \%$ of the total sample. Half of the respondents reported willingness to use a preventive medication if available.

Logistic models to predict alcohol abuse, condom use and HIV testing are shown in Table 1. Analysis revealed a predictive model for alcohol excess use that was driven by young age $(p<0.001)$ and protective behaviours among women with children $(\mathrm{p}<0.029)$. Regarding condom use, younger women $(\mathrm{p}<0.026)$ and women with a new sexual partner within the last 6 months $(\mathrm{p}<0.001)$ were least likely to use condoms. The women were more likely to use condoms if they were in a stable primary relationship $(\mathrm{p}<0.002)$ and did not have casual sexual partners $(\mathrm{p}<0.027)$; and, the longer the duration of the relationship, the greater the likelihood of condom use $(\mathrm{p}<0.020)$. In this model, having children was not a statically significant influence for condom use. Our analysis indicated that HIV antibody testing was more likely among young women $<25$ years of age $(\mathrm{p}<0.015)$ and by women who reported casual sexual partners $(\mathrm{p}<0.024)$. Also, women who made assumptions about knowing their partner's HIV status were more likely to have been tested at some time in the past $(\mathrm{p}<0.009)$. There were no statistically significant differences within the sample regarding knowledge of pre-exposure prophylaxis or willingness to use such medication if it were available to them.

\section{DISCUSSION}

In this time-site stratified survey of women attending bars, cafés and beer gardens in central Prague, we found critical markers for problematic alcohol consumption in terms of the frequency and volume of alcohol consumed and cautionary responses to the CAGE screen. From prior ethnographic experience in similar venues, we suspect that respondents may have estimated alcohol consumption over an average afternoon or evening, that is, over 3-5 hours rather than the standardized 2-hour window that was specified in the survey. Despite this leniency, the data indicates that Prague women are consuming on average 2.5 to 3 liters of beer twice weekly, which far exceeds recommendations for alcohol consumption.

Czech society has a long tradition of consuming beer and spirits as part of social interactions, lenient cultural norms toward problematic alcohol use $(2,3)$, and a history of men being more likely than Czech women to abuse alcohol (32). Even so, social, economic, and political transitions may have fostered greater alcohol consumption among women $(9,32)$. Our findings suggest that women less than 25 years of age, women over 50 years of age, and women who were self-identified as a sexual minority, experience greater risks of alcohol excess. In contrast, women with children showed a protective, negative association to alcohol use. While we are unable to determine long-term trajectories of alcohol use from this cross-sectional survey, the data signal concern for the possibility of escalating alcohol use and alcohol-related health consequences for women in Prague.

An HIV risk differential emerged for heterosexual women with new, casual or serially monogamous sexual partners of short-term duration. Such sexual encounters without barrier protection, regardless of alcohol and/or drugs influences, expanded HIV risk vulnerabilities $(33,34)$. Very few in this sample discussed HIV status or prior HIV antibody testing with their sexual partners. Without discussion of HIV status or by relying on ungrounded presumptions of their partners' HIV status suggested the respondents had little awareness of HIV risk or they did not perceive HIV risk as personally relevant. Without soliciting more detailed information, understanding the reasons for not testing for HIV status will remain unknown. However, the historically low prevalence of HIV and lack of social media attention to raise awareness (21) may mislead the women to believe they are not at risk. As a contrast, the women who claimed identities as a sexual minority (homosexual, bisexual or transsexual) may be at less risk for acquiring HIV because partner fidelity and comparatively longer duration of their primary relationships provide a degree of protection. Slightly higher but not statistically significant rates of reported HIV testing may reflect greater awareness of HIV conditions from information shared through the lesbian-gay-bisexual-transgender (LGBT) media or from spending time in LGBT-oriented venues. 
Table 1. Results of log-likelihood models for alcohol excess, condom use, and HIV antibody testing by the community-based sample of women in Prague social venues

\begin{tabular}{|c|c|c|c|c|}
\hline & Logit Coefficients & Odds Ratios & $p$ & Confidence Intervals \\
\hline \multicolumn{5}{|l|}{ Alcohol excess } \\
\hline Age $<25$ & 1.76 & 5.83 & $<0.001^{*}$ & $2.31-14.66$ \\
\hline Education & -0.16 & 0.85 & 0.725 & $0.348-2.08$ \\
\hline Marital status & -0.27 & 0.76 & 0.535 & $0.32-1.81$ \\
\hline Children & -1.24 & 0.24 & $0.029^{* *}$ & $0.06-0.86$ \\
\hline \multicolumn{5}{|l|}{ Condom use } \\
\hline Age $<25$ & -1.31 & 0.27 & $0.026^{*}$ & $0.08-0.86$ \\
\hline Education & 0.82 & 2.26 & 0.148 & $0.75-6.86$ \\
\hline Marital status & 2.14 & 8.56 & $<0.001^{*}$ & $2.67-27.37$ \\
\hline Children & -0.66 & 0.51 & 0.418 & $0.10-2.56$ \\
\hline No casual partner & 1.32 & 3.43 & $0.027^{* *}$ & $1.15-10.27$ \\
\hline 1 casual partner & -2.04 & 0.13 & $0.001^{*}$ & $0.03-0.42$ \\
\hline 2 or more casual partners & -2.83 & 0.06 & $0.032^{*}$ & $0.00-0.78$ \\
\hline Duration of relations & 0.86 & 22.13 & $0.020^{* *}$ & $1.62-301.51$ \\
\hline \multicolumn{5}{|l|}{ HIV testing } \\
\hline Age $<25$ & -1.09 & 0.34 & $0.015^{*}$ & $0.14-0.81$ \\
\hline Education & -0.56 & 0.57 & 0.187 & $0.25-1.31$ \\
\hline Marital status & 0.19 & 1.21 & 0.647 & $0.53-2.76$ \\
\hline Children & -0.13 & 0.88 & 0.836 & $0.26-2.91$ \\
\hline Casual partners & 0.94 & 2.57 & $0.024^{*}$ & $1.13-5.84$ \\
\hline Primary partner & -2.03 & 0.13 & $0.032^{*}$ & $0.02-0.84$ \\
\hline Known HIV status & -1.49 & 0.23 & $0.009^{*}$ & $0.07-0.68$ \\
\hline
\end{tabular}

*Statistical significance; **Protective association

\section{Limitation}

While our recruitment strategy aimed to access relatively difficult-to-reach populations, especially non-heterosexual women and men from an area of relatively high affluence in Prague, this study may not be generalized for behaviours found in other Czech cities, and the high level of educational attainment of this sample may also reflect the narrow breadth of this female Czech sample. Very few in this sample discussed HIV status or prior HIV antibody testing with their sexual partners.

Recruitment in social venues like bars, pubs, and clubs provided a safe setting for less restrained behaviours where pleasureseeking, disinhibition and relaxation promote interaction with others. It is possible that this sample of women may be overly represented by individuals with high alcohol consumption and/ or riskier sexual behaviour compared to Czech women found in the general population. The notion that women may consume emotion-altering substances in an effort to sustain, change or repair interpersonal connections is consistent with the Relational Model of Women's Psychological Development that suggests interpersonal connectedness among women's social roles and psychological wellbeing (35). Applying such a perspective to our survey recruitment, social venues may be a vehicle for alcohol consumption and interpersonal connection, or an example of group solidarity by refusal to participate in a survey (36).

The survey questionnaire was intended to be brief so that it would not interfere with the business and activities within the venues. Thus, many explanatory questions were not asked, for example, contraception preference and utilization patterns; onset of alcohol, drug use, or smoking (37). More importantly, life history including adverse life events and traumas were not queried. The survey did not assess motivations for condom use and HIVtesting or lack thereof, which would add greater understanding to this discussion. We focused on the highest-risk behaviours, so we did not obtain information to explain all risk behaviours.

\section{Strengths}

While there are studies drawn from nationally representative samples about sexual behaviours (38) or use of alcohol and recreational drugs (5), most of the existing data about Czech women's sexual behaviour in relation to alcohol or drug use comes from treatment-seeking, clinical populations. Our study is the first to assess and identify sexual minority status among Czech women. Notably, the community-based sample represents an important audience for education and prevention efforts regarding protective sexual behaviours.

\section{CONCLUSIONS}

From this study, we find that Czech women are at increased risk for HIV infection due to unprotected sexual encounters and disinhibition by alcohol excess. Lack of condom use with casual sex, low reported HIV dialogue with sexual partners and low 
HIV testing rates are signs that HIV protective behaviours need reinforcing even among the well-educated women of Prague. Although pre-and post-exposure prophylaxis is still new in many parts of the world, condom use and HIV testing are the mainstays of HIV prevention. We recommend further research toward solutions for reducing HIV risk among Czech women and policy considerations for pre-and post-prophylaxis in the future HIV prevention strategies.

Minimizing substance abuse relies upon effective prevention and diversions from excessive use. As we had limited data to identify mediators of substance use/abuse from our sample, we recommend further research with Czech women to learn more about substance use, especially about psychosocial and environmental factors that contribute to excessive use of alcohol in women's lives. Also, we would suggest consideration of programmes for screening, brief intervention, and referral to treatment (SBIRT) for women at risk of AOD excess, SBIRT has been found to be an effective public health approach for identifying risk and instituting early alcohol and drug treatment when needed $(39,40)$.

\section{Acknowledgements}

Research and writing were funded by NIH/NIDA T32 DA026400, Training Program on Addiction Medicine in Primary Care, with additional support from the National Institute of Mental Health (P30 MH58107).

\section{Conflict of Interests}

None declared

\section{Ethical Standards}

The study protocol was reviewed and approved by the Office of Human Research Protection at the University of California, Los Angeles. It adheres to the ethical standards set forth in the Belmont Report and the Helsinki Declaration.

\section{REFERENCES}

1. Stehlíková D, editor. Country Progress Report: Czech Republic. Global AIDS Response Progress Report 2012. Reporting period: January 2010 - December 2011. Prague: National AIDS Programme; 2012.

2. Hall TM. Pivo at the heart of Europe: beer-drinking and Czech identities. In: Wilson TM, editor. Drinking cultures: alcohol and identity. Oxford: Berg; 2005. p. 65-86.

3. Kubička L. Alcohol use in the country with the world's highest per capita beer consumption - the Czech Republic. Addiction. 2006 Oct;101(10):1396-8.

4. Šeblová J, Polanecký V, Šejda J, Studničková B. Trends in substance abuse by teenagers in the Czech Republic. J Emerg Med. 2005 Jan;28(1):95-100.

5. Csémy L, Sovinová H, Procházka B. Alcohol consumption and marijuana use in young adult Czechs. Cent Eur J Public Health. 2012 Dec;20(4):2447.

6. Colfax G, Shoptaw S. The methamphetamine epidemic: implications for HIV prevention and treatment. Curr HIV/AIDS Rep. 2005 Nov;2(4):194-9.

7. Cheng WS, Garfein RS, Semple SJ, Strathdee SA, Zians JK, Patterson TL. Differences in sexual risk behaviors among male and female HIVseronegative heterosexual methamphetamine users. Am J Drug Alcohol Abuse. 2009;35(5):295-300.

8. Kubička L. Jaroslav Skála (1916-2007): an international figure and doyen of Czech alcohol dependence treatment. Addiction. 2008 Jul;103(7):122930.

9. Kubička L, Csémy L, Kožený J. Prague women's drinking before and after the 'velvet revolution' of 1989: a longitudinal study. Addiction. 1995 Nov;90(11):1471-8.
10. Mravčík V, Nechanská B, Št’astná L. Outpatient care for substance users and addicts in the Czech Republic in Health Statistics since 1963. Epidemiol Mikrobiol Imunol. 2011 Jun;60(2):64-73. (In Czech.)

11. Kastankova $\mathrm{V}$. Increasing sexually transmitted disease rates among prostitutes in the Czech Republic. J Community Health. 1995 Apr;20(2):219-22.

12. Griffiths P, Mravčík V, Lopez D, Klempová D. Quite a lot of smoke but very limited fire - the use of methamphetamine in Europe. Drug Alcohol Rev. 2008 May;27(3):236-42.

13. Gregorová P, Weiss P, Unzeitig V, Cibula D. Contraceptive behaviour of Czech and Romanian women: comparison of representative national samples. Eur J Obstet Gynecol Reprod Biol. 2011 Feb;154(2):163-6.

14. Nash R. Old entitlements and new dependencies: family versus state in the Czech Republic. In: Hall TM, Read R, editors. Changes in the heart of Europe: recent ethnographies of Czechs, Slovaks, Roma, and Sorbs. Stuttgart: Ibidem-Verlag; 2006. p. 93-110.

15. Cibula D. Women's contraceptive practices and sexual behaviour in Europe. Eur J Contracept Reprod Health Care. 2008 Dec;13(4):362-75.

16. Haimovich S. Profile of long-acting reversible contraception users in Europe. Eur J Contracept Reprod Health Care. 2009 Jun;14(3):187-95.

17. Fronteira I, Oliveira da Silva M, Unzeitig V, Karro H, Temmerman M. Sexual and reproductive health of adolescents in Belgium, the Czech Republic, Estonia and Portugal. Eur J Contracept Reprod Health Care. 2009 Jun;14(3):215-20.

18. Záhumenský J, Zmrhalová B, Jilich D, Driák D, Rozsypal H, Machala L, et al. Analysis of a group of HIV positive women who gave birth in the Czech Republic. Ceska Gynekol. 2007 Aug;72(4):228-32. (In Czech.)

19. National Institute of Public Health. Press report of the National Reference Laboratory for HIV/AIDS: HIV/AIDS trends and incidence in the Czech Republic in 2012. Prague: National Institute of Public Health; 2013. (In Czech.)

20. Stehlíková D, editor. Country Progress Report: Czech Republic 2010. United Nations General Assembly Special Session on HIV/AIDS Declaration of Commitment. Reporting period: January 2008 - December 2009. Prague: National AIDS Programme; 2010.

21. Kvášová S, Nečas V. HIV/AIDS in the Czech Media (1996-2009). Adiktologie. 2011;11(4):200-6. (In Czech.)

22. Parsons JT, Grov C, Kelly BC. Comparing the effectiveness of two forms of time-space sampling to identify club drug-using young adults. J Drug Issues. 2008;38(4):1061-81.

23. Binson DA, Blair J, Huebner DM, Woods WJ. Sampling in surveys of lesbian, gay, and bisexual people. In: Meyer IH, Northridge ME, editors. The health of sexual minorities: public health perspectives on lesbian, gay, bisexual and transgender populations. New York: Springer; 2007. p. $375-418$.

24. Iguchi MY, Berry SH, Ober AJ, Fain T, Heckathorn DD, Gorbach PM, et al. Sexual Acquisition and Transmission of HIV Cooperative Agreement Program (SATHCAP), 2006-2008 [United States] Restricted Use Files. ICPSR29181-v1. Ann Arbor, MI: Inter-university Consortium for Political and Social Research; 2010.

25. Bradley KA, DeBenedetti AF, Volk RJ, Williams EC, Frank D, Kivlahan DR. AUDIT-C as a brief screen for alcohol misuse in primary care. Alcohol Clin Exp Res. 2007 Jul;31(7):1208-17.

26. Mayfield D, McLeod G, Hall P. The CAGE questionnaire: validation of a new alcoholism screening instrument. Am J Psychiatry. 1974 Oct;131(10):1121-3.

27. Aertgeerts B, Buntinx F, Kester A. The value of the CAGE in screening for alcohol abuse and alcohol dependence in general clinical populations: a diagnostic meta-analysis. J Clin Epidemiol. 2004 Jan;57(1):30-9.

28. Ewing JA. Detecting alcoholism. The CAGE questionnaire. JAMA. 1984 Oct 12;252(14):1905-7.

29. Sovinová $\mathrm{H}$, Csémy L. The Czech audit: internal consistency, latent structure and identification of risky alcohol consumption. Cent Eur J Public Health. 2010 Sep;18(3):127-31.

30. Kubisová D, Dlouhý P, Rambousková J, Andel M. Absence of protein-energy malnutrition in Prague homeless. Int J Public Health. 2008;53(1):5763.

31. Hamilton LC. Statistics with Stata: updated for version 12. 8th ed. Boston: Brooks/Cole, Cengage Learning; 2013.

32. Popova S, Rehm J, Patra J, Zatonski W. Comparing alcohol consumption in central and eastern Europe to other European countries. Alcohol Alcohol. 2007 Sep-Oct;42(5):465-73.

33. Kretzschmar M, Morris M. Measures of concurrency in networks and the spread of infectious disease. Math Biosci. 1996 Apr 15;133(2):165-95.

34. Mercer CH, Aicken CR, Tanton C, Estcourt CS, Brook MG, Keane F, et al. Serial monogamy and biologic concurrency: measurement of the gaps 
between sexual partners to inform targeted strategies. Am J Epidemiol. 2013 Jul 15;178(2):249-59.

35. Covington S, Surrey J. The relational model of women's psychological development: implications for substance abuse. In: Wilsnack RW, Wilsnack SC, editors. Gender and alcohol: individual and social perspectives New Brunswick, NJ: Rutgers Center of Alcohol Studies; 1997. p. 335-51.

36. Covington SS. Helping women recover: a comprehensive integrated treatment model. Alcohol Treat Q. 2000;18(3):99-111.

37. Láchová J. European Health Interview Survey in CR - EHIS CR: Smoking and tobacco smoke exposure. Aktuální Informace ÚZIS ČR. 2011(2):1-11. (In Czech.)

38. Weiss P, Zveřina J. Sexual behaviour in the Czech Republic - situation and trends. Prague: Portál; 2001. (In Czech.)
39. Babor TF, McRee BG, Kassebaum PA, Grimaldi PL, Ahmed K, Bray J. Screening, Brief Intervention, and Referral to Treatment (SBIRT): toward a public health approach to the management of substance abuse. Subst Abus. 2007;28(3):7-30.

40. Madras BK, Compton WM, Avula D, Stegbauer T, Stein JB, Clark HW. Screening, brief interventions, referral to treatment (SBIRT) for illicit drug and alcohol use at multiple healthcare sites: comparison at intake and 6 months later. Drug Alcohol Depend. 2009 Jan 1;99(1-3):280-95.

Received September 12, 2013 Accepted in revised form January 20, 2015 